\title{
Editorial
}

\section{What We Need Is a Knowledge Management Perspective}

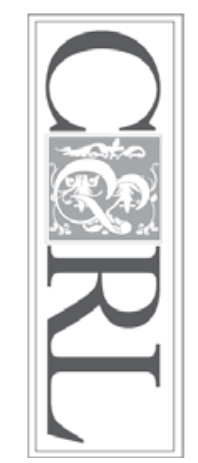

One of the most cited articles in College $\mathcal{E}$ Research Libraries over the last ten years has been Charles Townley's "Knowledge Management and Academic Libraries," which was published back in January 2001. I found this out recently when we peer-reviewed and accepted the forthcoming article "A Citation Analysis of College \& Research Libraries: Comparing Yahoo, Google, Google Scholar, and ISI World of Knowledge with Implications for Promotion and Tenure" by Charles Martell. Martell's article provides an interesting look at the use of articles from our journal, including a table of the top ten most cited $C \mathcal{E} R L$ articles in the last ten years.

If you want to read Martell's forthcoming article, you can. Like most journals we have a backlog of accepted articles waiting for formal publication. Martell's article was accepted in December 2008, but it will not be formally published in CERL until July 2009 or later. However, you do not have to wait. You can find it right now in its final manuscript form by going to our new pre-publication service at the College \& Research Libraries Web site. This service makes CERL manuscripts available "open access" within days after acceptance.

I had not read Townley's article on knowledge management before Martell alerted me to it. I would have benefited from reading it sooner. (Remember the value of literature reviews.) I stumbled onto the idea of knowledge management all on my own some years ago as I tried to make sense of the changing nature of collection development work in academic libraries. It seemed to me then, and it seems even more so today, that academic librarians need to extend the range of their responsibilities and expertise well beyond the traditional, almost exclusive, focus on collecting and servicing the formally published scholarly literature. It is true that our special collections librarians and archivist have paid attention to more unique and ephemeral material, but there is so much more "explicit" and even more "tacit" knowledge coming from our faculty and students that escapes our attention. The field of knowledge management provides a useful perspective and tools for addressing this broader range of librarian responsibility.

With the rapid development of digital information technology and the Internet, an individual's or group's ability to create and disseminate information in an un-mediated manner, to self-publish, has exploded. One of the best descriptions I have read about this more democratic and participatory information environment and how it filled the Internet with an extraordinary amount and range of content in just one decade is Kevin Kelly's "We Are the Web" (Wired magazine, August 2005). The ability to create and share information and knowledge is literally at our finger tips. Do an inventory or even a cursory survey of the types and amount of useful, sharable digital information being generated by faculty, students, and staff at your university or college, and I can wager you will be impressed by the variety, amount, and casual approach to storage and preservation of this content. 
The institutional repository movement in academic libraries is one attempt to meet this knowledge management challenge by helping to collect, organize, and preserve a broader range of content, now most often in born-digital form. Just as we created traditional library facilities to store print material, we now have digital repositories to hold digital content. The shelving and the digital asset management tools we deploy are important, but what really matters is creating effective service models to fill the stacks or the digital repository with the appropriate content. The old service model for collection management might have filled the stacks, but it is not working to fill the institutional repository. What is needed is a much more proactive, flexible, knowledge management perspective and approach to designing the new service model in academic libraries.

This is an opportune time for academic librarians to extent themselves and become more proactive, more connected and social in the knowledge-making process. The current interest in library support for e-science is another interesting manifestation of a new knowledge management perspective. It wasn't long ago, as little as ten years ago, when a basic activity in any academic science library was the acquisition and servicing of the current print issues of core science journals. Science faculty stopped in the library facility frequently to browse and read the latest issues of their field's journals, the issues carefully arranged and cared for by the library staff. All that is gone now, with the science journal literature almost entirely online. What are science libraries to do? The new and rather daunting responsibilities emerging in science librarianship include participation on research teams, science data curation, and helping manage the whole life cycle of scientific information from research and discovery to publication and data archiving. This sounds like the fruition of knowledge management to me.

Joseph J. Branin Editor, College \& Research Libraries 